\title{
Child participation: Child contributors' reflections on their experiences
}

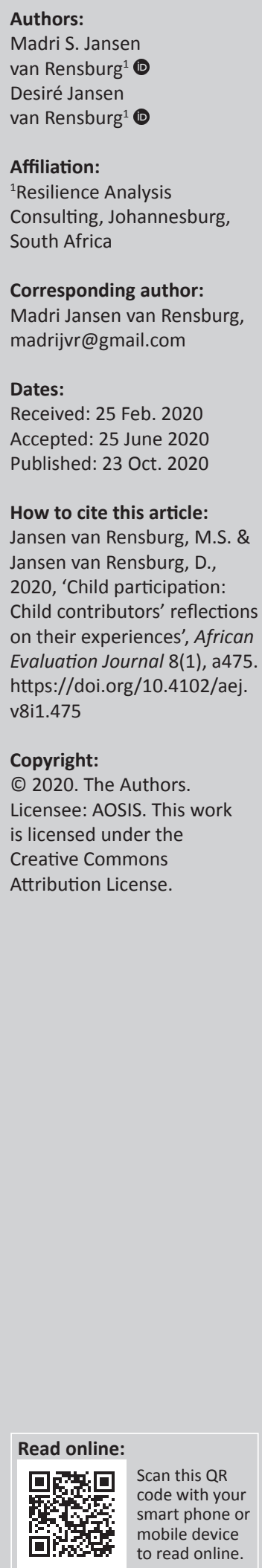

Background: Child participation is critical for evaluation in the light of all Sustainable Development Goals (SDGs) and leaving no one behind. Resilience Analysis Consulting developed a child-friendly version (CFV) of the National Child Participation Framework (NCPF). To ensure participation and optimal use of the document, children were included in all aspects of the document development.

Objectives: In this study children reflect on their experiences. This provides insight for document development and more widely into child participation in interventions for children and the evaluation of such interventions. It further highlights the value of child participation and encourages evaluators to include children.

Methods: The children who assisted in the development of the document were asked to reflect on the process and their experiences through an open-ended survey. Scales were used to investigate the benefits. Open-ended questions were thematically analysed.

Results: The experiences included the following main themes: (1) enjoyment of the project activities, (2) satisfaction with contributions, (3) learning new information, (4) being more aware of children's rights and participation in society, (5) contributing to other children's lives and (6) the importance of recognition and being valued. Seeing their ideas, artwork and recommendations in print made them feel that they were taken seriously.

Conclusion: A participatory approach when developing materials for children enhances the uptake and dissemination of information. Children contribute unique and valuable perspectives to the evaluation process. Evaluators wrongly assume negative consequences, preventing them from including children, while children report positive outcomes. The process empowered child participants.

Keywords: Evaluation; Child; Participation; Child-friendly documents; SDGs.

\section{Introduction}

Participatory approaches in evaluation have been debated and advocated for many years (Brandon 1998; Greene 1987; Gregory 2000; Daigneault 2014), and methodologies to ensure the participation of various stakeholders have been developed (Campilan 2000; Chambers 2009; Guijt 2014). Participation is important at all stages of the process - planning, development of methodologies (and tools), data collection, analysis and reporting of results. The utility of the results and probability of transformative change increases when reports and other products (such as guidelines and documents) are developed in close collaboration with stakeholders. Children make up an important stakeholder group that is often excluded from evaluation activities.

All children have the right to participation. This includes active participation in aspects and decisions that affect them, including policies. Child participation also helps realise other child rights, for example, education and healthcare. Everyone involved with and working with children needs to promote, protect and respect children's rights (Save the Children South Africa 2019; Save the Children South Africa/Republic of South Africa National Department of Social Development [SCSA/DSD] 2018).

Globally, this obligation is specified in the United Nations Convention on the Rights of the Child (CRC) (United Nations 1990). The African Charter on the Rights and Welfare of the Child (African Union 1999) stipulates child participation on the continent. The Republic of South Africa

Note: Special Collection: SAMEA 7th Biennial Conference 2019. 
included the rights of children in the constitution (RSA 1996) and the Children's Act (38 of 2005). To be meaningful, it is important that participation is in the best interest of the child, safe and ethical (Save the Children South Africa 2019; SCSA/ DSD 2018).

The voices of children are needed in different spaces. These spaces include the home and family, education, health facilities, the justice system, child protection work, the community and local and national government (including policies) (Save the Children South Africa 2019; SCSA/DSD 2018). As evaluations are conducted for development processes across the different spaces in which child participation is needed, it is critical for evaluators to include child participants. Children offer a unique and valuable perspective in developmental programmes and the evaluation of these efforts (SCSA/DSD 2018). Child participation is not only critical when children are direct beneficiaries, but they also provide insight into all evaluations and ensure that no one is left behind. All 17 Sustainable Development Goals (SDGs) include children indirectly. Some indicators for SDGs 1, 2, 3, 4, 5, 6, 7, 8, 10, 13, 16 and 17 measure outcomes for children exclusively. That is, 35 of the 232 specific indicators directly relate to children (see Figure 1). Evaluations including any of these 12 SDGs should report on children. However, most implementers and countries have insufficient data or evaluation studies to assess whether they are on track to achieve the SDG targets for children (UNICEF 2018). In general, evaluators do not report data for children, and the data do not include the voices of children. The participation of children is critical and should focus on active contributions and not only on token (insincere and symbolic) participation. It is essential that all aspects of programmes and projects include child contributions (from planning and design to dissemination of information and policies).

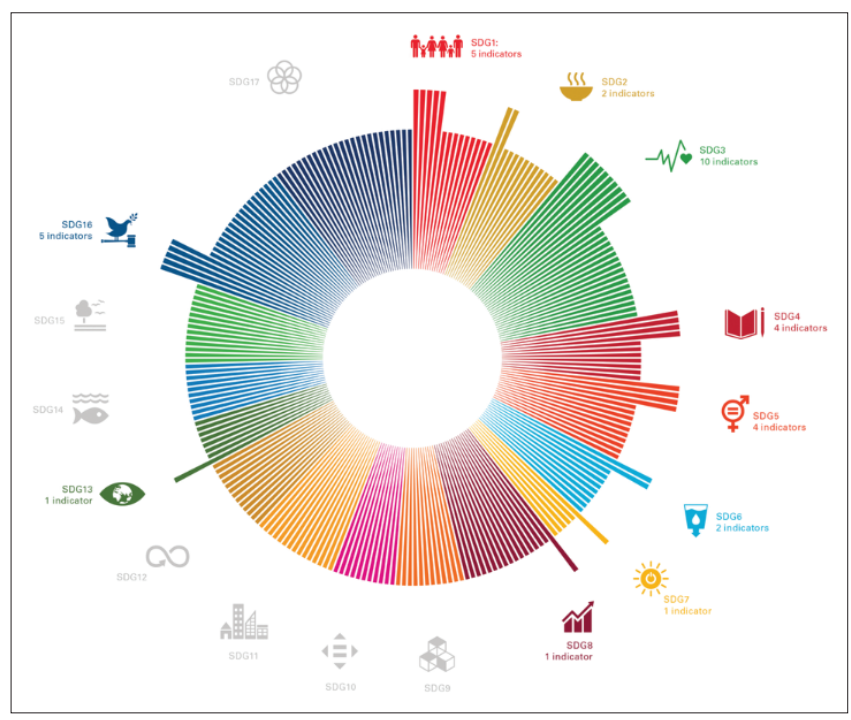

Source: UNICEF, 2018, Briefing notes on SDG global indicators related to children, viewed 16 November 2018, from https://data.unicef.org/resources/sdg-global-indicators-related-tochildren/.

SDG, Sustainable Development Goal.

FIGURE 1: Number of child-focussed indicators within each Sustainable Development Goal.
The case described here focuses on the child participants making contributions to all stages of the development of a child-friendly version (CFV) of the National Child Protection Framework (NCPF) of South Africa (Save the Children South Africa 2019). Save the Children South Africa (SCSA) and the National Department of Social Development (DSD) developed the NCPF (SCSA/DSD 2018). The NCPF guides participation of children for meaningful change for government, civil society and children and other sectors (SCSA/DSD 2018). A CFV was commissioned to ensure that the NCPF is accessible for all children (Save the Children South Africa 2019). This document is both visually engaging for children and imparts information on a level that is relevant to children of different ages (Save the Children South Africa 2019). Resilience Analysis Consulting included children in the process to ensure practical participation at all stages and steps of the process (including concept development, format of the material, creating artwork, editing the content and using appropriate language). The CFV uses an innovative format, an activity book, that actively engages children. This enables children (as young as 3 years old) and youth to learn about child participation. Educators and facilitators of child participation sessions can also use the book. Games and case study activities can be used for discussion of topics by groups of children (Save the Children South Africa 2019).

The CRC was launched 31 years ago (Lansdown 2019). Since then the demand for child participation has increased; however, not much is known about the effects of participation on children. It is important to understand the implication of child consultation and participation in studies. The first step in this (and the focus of this article) is to listen to children reflecting on their participation experiences. The next step (and the topic of future studies) is to assess the value of CFVs of documents and policies for children. This study reports on the reflections and perspectives of the child consultant groups. This will inform evaluators about the competence they need and the value of including child contributors in evaluations.

\section{Literature review}

Participation refers to 'the process of sharing decisions which affect one's life and the life of the community in which one lives' (Hart 1992:5). The NCPF in South Africa defines child participation as the active involvement of children in the decisions, processes, programmes and policies that affect their lives' (SCSA/DSD 2018:4). In the South African context, a child is 'anyone under the age of 18 years' as described by the Children's Act (South Africa Children's Act 2005). This is also the defining age used in Africa (African Union 1999).

Children are still viewed today as vulnerable, inexperienced and lacking the skills necessary to deal with complex issues and make decisions (Björnsdóttir \& Einarsdóttir 2018; Driskell 2002; Hörschelmann \& Van Blerk 2011; James, Jenks \& Prout 1998). There has been a fear that children's participation risks their safety and could be unethical. This has resulted in organisations and governments generally acting for children rather than with them, neglecting their 
potential contributions (Freeman \& Tranter 2011). Different emphases have been placed on the process and outcomes of child participation (Liebel 2012). The model of Lundy (2007) stipulates that for true participation four elements need to be fulfilled: (1) space for children to express their views, (2) children must be allowed to express their views and given a voice, (3) an audience that is willing to listen to the views and (4) influence or the understanding that views must be considered (Lundy 2007). Hart (1992) developed the ladder of participation; the bottom rungs of the ladder include the provision of information and consultation without a guarantee of impact on outcomes and thus represent lesser forms of participation. The top rung is reached when adults and children share decision-making (see Figure 2 for Hart's ladder of child participation).

The call for child participation in research and evaluation is not new. Many evaluators have advocated for the inclusion of children as active participants in evaluation studies (Lansdown 2005, 2014, 2019; Samaranayake \& Zaveri 2014). Some researchers are of the view that true child participation is almost

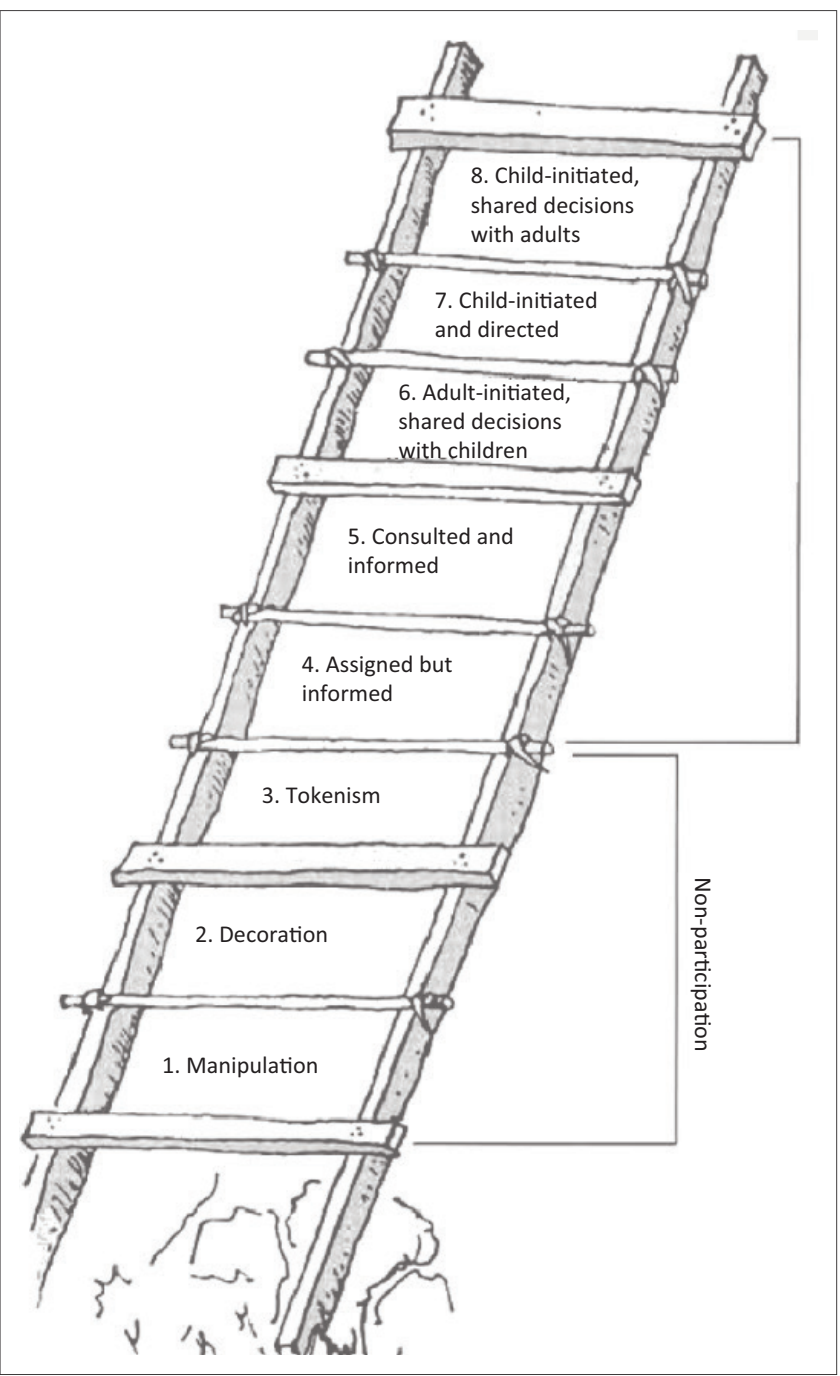

Source: Hart, R., 1992, 'UNICEF', in Children's participation: From Tokenism to citizenship Innocenti Essays, p. 4, viewed 22 November 2019, from http://www.unicef-irc. org/ publications/pdf/childrens_participation.pdf.

FIGURE 2: Ladder of child participation by Hart. impossible to achieve (Baaz 2005; Björnsdóttir \& Einarsdóttir 2018; Cooke \& Kothari 2002; Hickey \& Mohan 2004; Mikkelsen 2005). Some studies have focused more on guidelines regarding how to enhance participation by children or child-to-child projects (Boyden \& Ennew 1997; Lansdown 2014; Plan International 2018; Pradhan 2007; Wilkinson 2000). Other studies have focused on children as data sources, where data can be enhanced through their participation (Freeman \& Mathison 2009; Hart 1992, 1997; Loveridge 2010), or as part of the planning or execution of projects (Skivenes \& Strandbu 2006). This relates to a topic that has received much attention: the description of ethics involved in child participation (Powell et al. 2012; Wilkinson 2000). There remains a lack of understanding on how to implement child participation across different contexts (Björnsdóttir \& Einarsdóttir 2018; Clark \& Percy-Smith 2006; Gordon 2015). Healy (1998) described the difficulties in adapting child participation in the child protection context within current participation discourses. Currie and Heykoop (2012) developed guides to enable child participation in monitoring and evaluation of child protection interventions. The reality of child participation is therefore more complex as child participation lies not only on one level or participation in a single activity but also includes active involvement in different levels of decision-making about their involvement (in different roles) and the involvement of other children (Kirby et al. 2003). A more recent development is the attention given to gender sensitivity when dealing with children and ensuring that gender equality is addressed through the interactions with children. This is especially true when children are data sources for evaluations as the beneficiaries of projects (Samaranayake \& Zaveri 2014).

Participation benefits children themselves as well as the larger society. Participation gives children confidence and an increased sense of competence, whilst society becomes more sensitive towards child rights (Björnsdóttir \& Einarsdóttir 2018). In the study in Ghana by Björnsdóttir and Einarsdóttir (2018), children reported that they enjoyed participation. Children benefit from participation in building new friendships, increasing well-being from feelings of enjoyment from their participation and enhancing their critical thinking skills. Society benefits from sharing in the educational value of children's experiences of participation in governance as well as learning to appreciate the value of children's contributions and voices (Björnsdóttir \& Einarsdóttir 2018).

Björnsdóttir and Einarsdóttir (2018) in their study in Ghana highlighted the barriers that children identified in becoming participants in their society. One barrier is cultural ideas, such as adults' concerns about listening to children's voices. Child participants argued that adults disliked child rights in general. Secondly, adults were regarded as being uninformed about child participation. They believe that children will become arrogant, stubborn and disrespectful towards elderly people. Children might be prevented from voicing their opinions and making decisions and were valued less than other people in society. Finally, the authorities failed 
to implement frameworks, guidelines and laws on child participation.

Fanelli, Musarandega and Chawanda (2007) studied child participation to determine the challenges that children face in the development of Zimbabwe's National Action Plan (NAP) for Orphans and Other Vulnerable Children. The NAP aimed to increase child representation on committees charged with implementing the plan. It enhanced child participation and created meaningful roles for children in various initiatives within the NAP. Their recommendations included developing child-friendly trainings (for children and adults) and policy information and ensuring child representation (Fanelli et al. 2007). These aspects were considered during the development of the 'adult' version of the NCPF in South Africa.

There is a scarcity of literature found for studies on child participants in developing child-friendly documents or reflections of child participants on their experiences in evaluation. In this study, children reflected on their participation and how this experience influenced them. It aimed to better understand the influence of child participation in developing child-friendly materials but is also applicable to wider applications of child participation in the development of materials, programmes and evaluations in general.

\section{Development process of the child-friendly document}

To understand the experiences, it is important to describe the process and participation of the child consultants. The term 'consultant' in this article specifically refers to a person who provides expert advice and is not a reflection on labour or employment. Child consultants for this study included those children who provided expertise, for example, as child artists or in editing the document for age appropriateness.

\section{Participants}

The CFV of the NCPF used a child participation process. Children were involved in the development of all aspects of the document - the decision on what content to include, drawing and painting visual elements, editing of the document and final testing appropriateness (Save the Children South Africa 2019). The following groups of children participated in different activities:

- Children from the SCSA project in Alexandra, who assisted with the development of the adult version of the NCPF, were included in the first consultation, during which they provided input regarding the content and format of the document as they had previous exposure to it.

- Child artists assisted with the design of child-friendly activities after briefings about the content. They were actively involved in selecting and developing visual materials for the document. They contributed to the conceptual aspects and testing of the activities at different stages of the study.
- An independent group of children edited, tested and validated various versions of the document to ensure that the content and visual elements were age appropriate.

- Individual, independent children were asked to test activities included in the document.

- Child advocates of SCSA provided feedback on the final version and assisted with decisions such as the front-page visual element. They provided input on the appropriateness of the layout of the document prior to finalising and printing.

Ethical aspects were very important during the development of the document. All team members signed and abided by Save the Children South Africa's child safeguarding code of conduct. All engagements with children were age appropriate, ethically sound and upheld child rights and the rights of research participants. All researchers had previous experience working with children. Informed consent was obtained from parents and caregivers prior to any engagements, and assent was obtained from the children themselves before any interactions.

\section{Process}

An iterative process was followed that included a revision of certain aspects and repeating tasks such as developing visuals and editing for language and comprehension. Figure 3 illustrates the stages in the process to develop the CFV.

\section{Research method and design}

This study includes reflections by the child consultants who developed the CFV of the NCPF. The study commenced after the CFV was finalised. The study did not use sampling, as the number of children who participated in the development of the CFV of the NCPF was small. All children responded to the request for information $(N=21)$.

The children who formed part of the initial discussions on content and format $(n=8)$ were part of an ongoing group of the organisation who also assisted in the development of the 'adult' version of the NCPF. They were specifically asked to

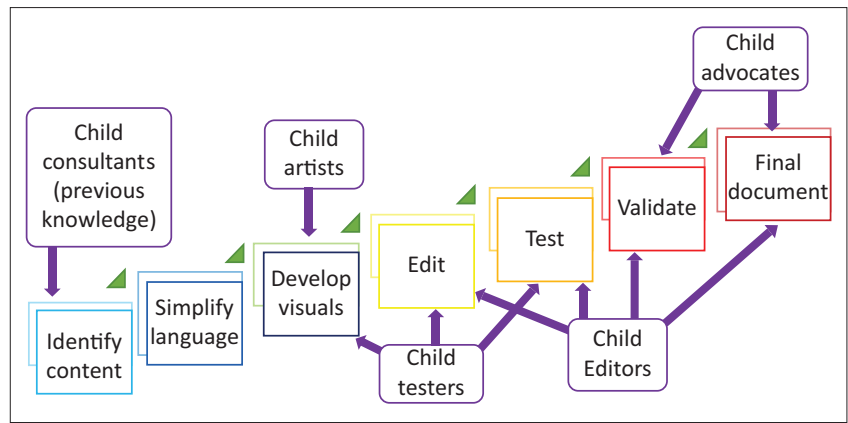

Source: Save the Children, 2019, 'National child participation framework: Child-friendly version', Save the Children South Africa, Pretoria, viewed 30 March 2020, from https:// resourcecentre.savethechildren.net/library/national-child-participation-framework-childfriendly-version.

FIGURE 3: Process of development of the child-friendly version of the National Child Participation Framework. 
provide conceptual inputs as they already had special insight into the document. Similarly, the group of advocates who did the final checks on the layout of the document were children who were familiar with child participation and acted in this capacity for SCSA on a continuous basis; some of them were part of the initial group who developed the NCPF ('adult' version).

The group of child artists $(n=8)$ and the group who did editing and tested the activities and narratives for age appropriateness $(n=5)$ were independent groups of children. They did not form part of any SCSA beneficiary or advocacy groups and were not previously involved with the development of the NCPF. The average age of the participants was 13.8 years $($ mode $=13)$, ranging between 8 and 18 years.

The two aforementioned groups (the SCSA group and the non-SCSA group) were engaged with in different ways. This was partially because of the fact that they are SCSA beneficiaries and undergo ongoing sessions that include reflections on their activities. The non-SCSA group were never part of any similar activity. They were a more neutral group that provided 'fresh' insights and more in-depth descriptions of their experiences.

The children who assisted were asked to reflect on the process and their experiences and contributions through open-ended surveys and in-depth discussions. Likert-type scales were used with open-ended explanations of experiences. Save the Children South Africa beneficiaries provided more informal feedback that related more to the process than their experiences and did not complete the scales. The data were entered into Excel and thematically analysed using grounded theory to determine the key themes. A child research consultant assisted in the analysis for the study. The results were presented to the participants to gain further insight, to validate the trustworthiness of the data and to ensure that the participants received feedback on the results.

The survey was administered by the team who developed the CFV of the NCPF (a conceptual developer and artist) and were familiar with the children through the process. Parents (or caregivers in the cases of foster children) signed written informed consent for the child to participate in the research study, and all children provided assent after being informed of the purpose and process of the research and ethical principles, including confidentiality, anonymity, privacy, voluntary participation and the right to withdraw.

\section{Ethical considerations}

This article followed all ethical standards for research without direct contact with human or animal subjects.

\section{Results}

The SCSA group (contextual and advocates) did not provide quantitative information on the experiences. This was because of the fact that they have internal ongoing processes that involve continuous reflections and debriefing. Their feedback mostly contained aspects such as opinions about the process during the engagements. The results of the other groups (artists and editors) are discussed in this section on formal feedback.

\section{Levels of enjoyment and satisfaction}

Both the artist and editors reported high levels of enjoyment. All the respondents rated the level of enjoyment as 'enjoyed mostly' or 'enjoyed very much'. None of the respondents reported not enjoying the participation or enjoying it a little (see Figure 4). The artists more frequently reported the highest level of enjoyment. The artists were doing a task that they were familiar with and an activity (making art) that they generally saw as a relaxing exercise, whilst the editors' tasks were more structured. The artists were able to see their products and the outcomes of the activities immediately. Although the full document and in some cases the completed scenes for some activities were only available later in the process, the visual elements that each was working on were rewarding immediately for the artists. For the editors, they only saw an edited portion and the satisfaction was delayed slightly. Both groups felt recognised and trusted, as evident in the following participants' quotes:

'I liked every single activity I did, I really enjoyed doing the activities, I liked where I drew the swimming pool and sand pit'. (child artist 1, gender undisclosed, 01 August 2019)

'I loved drawing for the documents'. (child artist 8, gender undisclosed, 01 August 2019

'I enjoyed being creative, sharing my skills'. (child artist 11, gender undisclosed, 01 August 2019)

The levels of satisfaction with their contributions were also very high, although slightly lower than the enjoyment levels (see Figure 5). The levels of satisfaction were higher for the editors than for the artists. The editors could see their input changing the product of the project for the better. They were satisfied with their contributions:

'I enjoyed helping them realise mistakes and providing my point of view'. (child editor 3, gender undisclosed, 01 August 2019)

'I enjoyed filling the word puzzles, I am glad that I participated in this'. (child editor 4, gender undisclosed, 01 August 2019)

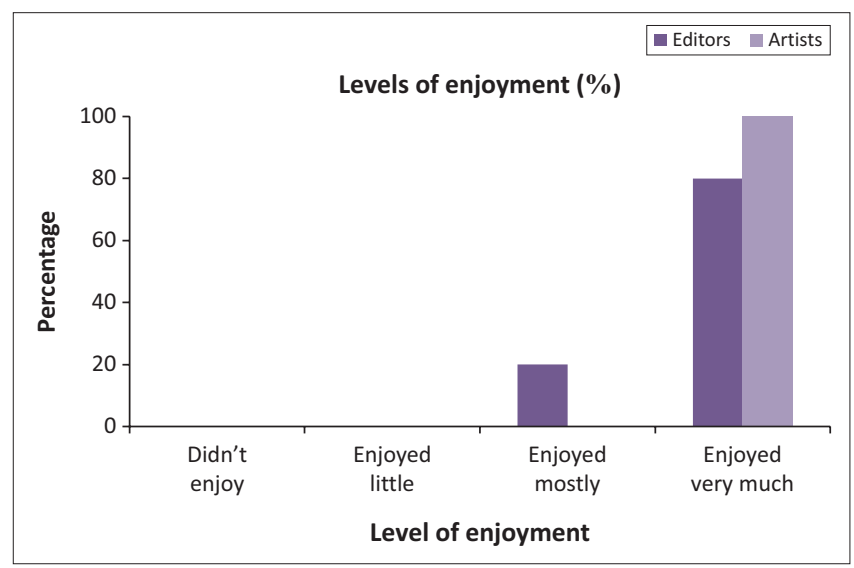

FIGURE 4: Levels of enjoyment in the project. 


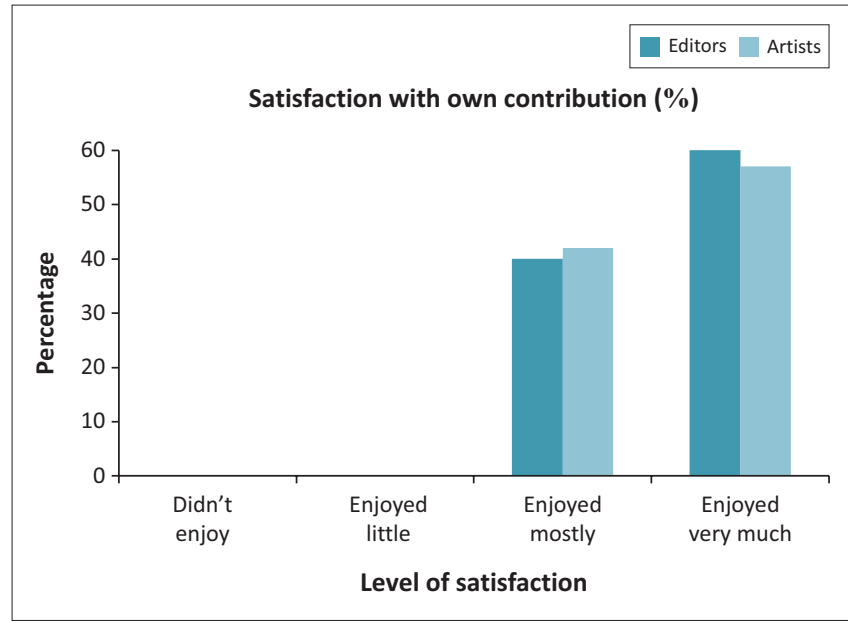

FIGURE 5: Levels of satisfaction with own contribution.

The reasons for the high levels of satisfaction and enjoyment were varied. In essence it was similar for the two groups, although being able to express themselves creatively rated higher for the artists. It must be noted that one of the editors also provided visuals. The editors were encouraged to contribute visuals to any of the work they were editing if they felt creative and inspired. The artists were also provided the opportunity to test the activities and provide opinions on the appropriateness and relevance of the materials. The specific elements that they were more satisfied with included the following.

The children enjoyed the project, specifically the following elements. The creative process was of special enjoyment and interest to the artists. They were instructed to draw visuals by using key cues (e.g. representing a child in court). Not only did they find the content interesting, but being given the freedom to express themselves creatively was also very satisfying, as shown in the following quote:

'It was something else I have never done before'. (child artist 10, gender undisclosed, 01 August 2019)

Being able to complete a specific visual or object that they could contribute to with their own skill and activities was very satisfactory:

'I enjoyed being able to draw for a children's book that was to show kids their rights, and I enjoyed the challenge of having to think of a picture to draw which best suited the topic I was given'. (child artist 12, gender undisclosed, 01 August 2019)

Being trusted to draw a specific subject or theme made the artists feel appreciated and trusted to complete a task on their own:

'I feel proudest of the picture I drew that became a colouring picture'. (child artist 8, gender undisclosed, 01 August 2019)

'I felt really proud of my picture to be used as an illustration. It was amazing'. (child artist 10, gender undisclosed, 01 August 2019)

The artist and editors reported feeling pleased experiencing the process itself and trusting the process without knowing the end product. They specified that being part of a team made the experience more enjoyable:
'I loved being creative, not knowing what the end of the project would look like'. (child artist 11, gender undisclosed, 01 August 2019)

'Just being part of the project to see what story my sketches create was the best part of being part of this project'. (child artist 11, gender undisclosed, 01 August 2019)

Child editors felt honoured to provide input. The trust that they were given to express their opinions was very satisfying. Trust was a key element for the children; they not only trusted the process but also wanted to be trusted to deliver their products:

'I am proud that I was able to do the activities and check if they work'. (child editor 3, gender undisclosed, 01 August 2019)

'I feel proud of myself that I can do it myself without no one helping me with my project'. (child editor 5 , gender undisclosed, 01 August 2019)

When asked about what they enjoyed the least, most children $(n=6,50 \%)$ answered that there was nothing they did not enjoy. The only comments were that one child did not enjoy the group discussions, whilst another felt that some graphics were very small in the final version.

When asked whether they would consider participating in future similar activities, all children answered positively. They all (100\%) indicated that they would recommend participation in similar projects to other children.

\section{Key themes}

The children learned new information that enhanced their understanding of their own rights and children's participation in general. The children learned about child rights, child participation and protecting themselves and other children. They learned about the subject of the intervention by being part of the evaluation. This is an important outcome in that the participants contributed to the new knowledge they gained by being part of the development process:

'We learned about our rights and the protection we need'. (child editor 2, gender undisclosed, 01 August 2019)

'About learning how to protect ourselves and how to help friends who are in the same problem'. (child editor 4, gender undisclosed, 01 August 2019)

The children further reported being more aware of the importance of children's rights and child participation in the larger society. Linking to the previous point on gaining information about a specific topic, the child participants also gained an understanding of community and the role of children:

'Projects like this can help a lot of children in need to learn about what the project teaches you about'. (child editor 4, gender undisclosed, 01 August 2019)

'A lot of children are suffering with issues that this project teaches you how to solve'. (child editor 2, gender undisclosed, 01 August 2019) 
The children took pride in contributing to other children's lives. This was on different levels, from their close friends to children in the wider society. The children not only became aware of society and the community, but they also felt that they played an important part in creating a better society. They became aware of the important role they could play in other children's lives:

'I enjoyed using my imagination and creating something from what was just a keyword'. I loved the fact that I did this to help children to see the brighter light and know what is right and wrong'. (child artist 9, gender undisclosed, 01 August 2019)

'I feel proud to $[b e]$ making a difference in other children's life'. (child artist 10, gender undisclosed, 01 August 2019)

This contribution to other children was valued very highly and was the most reported aspect in this study:

'I am proud that my sketches will be a trigger for someone's feelings'. (child artist 11, gender undisclosed, 01 August 2019)

'I make a difference'. (child artist 12, gender undisclosed, 01 August 2019)

'I will do this again as I love to give my time to make a difference and help other people'. (child editor 9, gender undisclosed, 01 August 2019)

The children's contributions were recognised and valued using different methods. They were all acknowledged in the book itself, and a certificate of appreciation and a small financial reward were provided. The children most of all appreciated being mentioned in the book's acknowledgements. Recognition of their contributions was very important for all the child consultants:

'The photo of me in the book, I was so proud of myself'. (child artist 10, gender undisclosed, 01 August 2019)

'I feel proudest of having the pictures I drew in the book'. (child artist 12, gender undisclosed, 01 August 2019)

\section{Discussion}

The four key elements for optimal participation mentioned by Lundy (2007) were all fulfilled in this study. This contributed to the high levels of participation, willingness to participate in future and being willing to recommend contribution also to other children. The children mentioned having space and opportunity, a voice, a willing audience and influence (Lundy 2007).

The children included from the SCSA beneficiaries (those who were involved in the original 'adult' version and the advocates who were involved in the final checking for context) were more aware of children's rights and child participation in general, as well as their own roles as active citizens, compared to the children in general.

The levels of enjoyment experienced by the non-SCSA group were remarkably high. This is similar to the study results by Björnsdóttir and Einarsdóttir (2018). The levels of satisfaction with their own contributions were also high. The artists scored higher for enjoyment and the editors more for satisfaction. The difference in the levels of enjoyment and satisfaction between artists and editors could probably relate to the type of tasks they were involved in. The artists were doing art activities that they found more enjoyable, whilst the editors did more cognitive activities that they felt proud and satisfied with. For example, a child editor commented as follows: 'I was very happy that I understood every activity I did' (1, gender undisclosed, 01 August 2019).

Other benefits included learning new information, being more aware of children's rights and participation in society, contributing to other children's lives and feeling recognised and being valued. Seeing their ideas, artwork and recommendations in print made them feel that their activities and voices were taken seriously.

The barriers to child participation include believing that children are not able to contribute meaningfully (Björnsdóttir \& Einarsdóttir 2018). The children commented that they felt empowered and were given the authority to complete the tasks assigned to them. 'I believe in my teacher; she wouldn't have signed [me] up for the project if it wasn't for a good cause' (child artist 11, gender undisclosed, 01 August 2019).

\section{Practical implications}

The main implication of this study is that meaningful child participation is possible. Participation can have many benefits for the child participants, other children and adults.

The results of this study further provide insights into the processes of child participation that can be followed. For example, it is important to ensure that the contributions of child participants are seen to benefit different levels (Kirby et al. 2003). The children felt that their activities contributed to themselves, their friends, other children and the wider society.

It further illustrates the importance of debriefing and reflections after projects. Providing children with feedback and recognising their contributions, especially in the final product, are an essential element in making child participants feel appreciated and valued.

\section{Limitations of the study}

Although the study had a small sample, it included all the participants of the activities. Follow-up studies should be included to validate the results of this study and to explore the experiences further.

A structured quantitative survey could be developed from this study results to enable wider use.

\section{Recommendations}

Models such as those by Hart $(1992,1997)$ and Lundy (2007) were relevant for this study. Combining these with an element looking at different levels of participation and 
influence (Kirby et al. 2003) could provide a comprehensive model for child participation.

Care was taken throughout the process to ensure that the work was ethically sound and that children were never compromised, exploited or felt this in any manner. This should be a priority in all future similar works. Constant revision of tasks and assessment of the levels of project fatigue should be undertaken. The children provided assent in addition to the caregiver consent. This ensured ownership, but more importantly acknowledged their rights to decisionmaking and participation.

The debriefing session with the child artists (with their caregivers) was an important event. The session not only allowed for debriefing of the possible effects of participation, but also provided a very important space to be acknowledged and to provide feedback on the value of the final document. It is important to include a session like this for all participant groups.

The children commented on the value of having their work acknowledged. Although this is standard practice for SCSA and Resilience Analysis Consulting, it is important to encourage this in all works where children participate. Recognition of individual contributions is very important. The children valued seeing their contributions, names and photos in the final document.

Although the testing and debriefing events provided opportunities for reflection and input on value, it is recommended that further formal testing and evaluation of outcomes and impact should be undertaken. It is recommended that this type of reflection becomes standard practice when dealing with child participants.

Assessing the use of the document would be difficult, but uptake (and demand) could give an indication of the usefulness locally and the value internationally. Future studies can include assessment of the value and the impact of documents developed for and by children.

\section{Conclusion}

A participatory approach when developing materials for children enhances the uptake and dissemination of information. This study of child consultants in a project to develop a CFV of the National Participation Framework (Save the Children South Africa 2019) confirmed that child participation has benefits for the participants, children in the wider society and for adults. Firstly, the participation of children ensured that the child-friendly materials developed were visually attractive to children (as designed by child artists) and that the content was easy to understand and relate to (ensured by the child editors) and suited to the context of children in South Africa. This is a significant movement towards the vision of the sector in South Africa and the CRC globally to have children as active actors (Lansdown 2019). The process left the child participants empowered. The children's experiences were positive; they enjoyed the process, and they felt satisfied with their contributions. Demand for this CFV document is high (from government departments, implementing partners and organisations outside South Africa). This is mainly because of the interactive format and content developed by the children for children.

The study results confirmed the models of different levels of participation (with the most developed form being 'child initiated, decision-making with adults'). The four elements of optimal participation (space, voice, audience and influence) were included in the process, and all were critical in the outcome (Lundy 2007). Combining these two models into a new model can further enhance participation in South Africa and more broadly on the African continent.

There were high levels of satisfaction and enjoyment expressed by all the participants. This was specifically related to the creative process, seeing a completed visual or piece of work, feeling appreciated and trusted, trusting the process without knowing the end product and being part of a team. They valued being provided an opportunity (including participation in activities outside their task, e.g. editors doing art work) that allowed them to express themselves. This highlights the importance of allowing children to participate in projects and not just portions of a study (e.g. as data sources). Children want to be part of the process and have their input valued (for them, to be mentioned and acknowledged in the final document). They not only trust the process and guidance, but also want to be trusted in return.

The reflections by the child participants clearly show how the outcomes of the project were not only relevant for them on a personal and individual level (learning new information and being recognised), but also made them aware of the plight of other children in the wider society and their role in contributing to those children's lives.

\section{Acknowledgements}

The authors acknowledge the contributions of the child artists, child editors and child content assistants for contributions to the development of the NCPF CFV and for participating in this study. They also would like to express their sincere thanks to Save the Children South Africa for allowing them to use innovative approaches in dealing with the assignment of developing the CFV of the NCPF.

\section{Competing interests}

The authors declare that they have no financial or personal relationships that may have inappropriately influenced them in writing this research article. 


\section{Authors' contributions}

M.S.J.v.R. conceptualised the study, conducted the survey and collected data. D.J.v.R. assisted in conceptualising the study and conducted the data analysis.

\section{Funding information}

This research received no specific grant from any funding agency in the public, commercial or not-for-profit sectors

\section{Data availability}

The data are ethically protected from being shared.

\section{Disclaimer}

The views and opinions expressed in this article are those of the authors and do not necessarily reflect the official policy of position of any affiliated agency of the authors.

\section{References}

African Union, 1999, African charter on the rights and welfare of the child, Organization of African Unity, Addis Ababa.

Baaz, M.E., 2005, The paternalism of partnership: A postcolonial reading of identity in development aid, Zed Books, New York, NY.

Björnsdóttir, P. \& Einarsdóttir, J. (eds.), 2018, 'Child participation in Ghana: Responsibilities and rights in what politics?: Youth and political engagement in Africa', in E. Oinas, H. Onodera \& L. Suurpää (eds.), What politics?, pp. 285-299, Brill, Leiden.

Boyden, J. \& Ennew, J. (eds.), 1997, 'Children in focus - A manual for participatory research with children', Save the Children Sweden, viewed 22 November 2019, from hanual.pdf.

Brandon, P.R., 1998, 'Stakeholder participation for the purpose of helping ensure evaluation validity: Bridging the gap between collaborative and non-collaborative evaluations', American Journal of Evaluation 19(3), 325-337. https://doi.org/ 10.1177/109821409801900305

Campilan, D., 2000, Participatory evaluation of participatory research. Forum on evaluation of international cooperation projects: Centering on development of human resources in the field of agriculture, International Potato Center, Nagoya, viewed 22 November 2019, from http://ir.nul.nagoya-u.ac.jp/jspui/bitstream/ 2237/8890/1/39-56.pdf.

Chambers, R., 2009, 'Making the poor count: Using participatory options for impact evaluation in chambers', in R. Karlan, D. Ravallion \& P. Rogers (eds.), Designing impact evaluations: Different perspectives, International Initiative for Impac Evaluation, viewed 22 November 2019, from https://www.3ieimpact.org/sites/ default/files/2017-11/Working_Paper_4.pdf.

Clark, A. \& Percy-Smith, B., 2006, 'Beyond consultation: Participatory practices in everyday spaces', Children, Youth and Environments 16(2), 1-9.

Cooke, B. \& Kothari, U., 2002, Participation: The new tyranny?, Zed Books, London.

Currie, V. \& Heykoop, C., 2012, Child Centred Accountability and Protection Evaluation (CAPE) guide for involving young people in monitoring \& evaluating child protection systems, The International Institute for Child Rights and Development (IICRD), Victoria.

Daigneault, P., 2014, 'Taking stock of four decades of quantitative research on stakeholder participation and evaluation use: A systematic map', Evaluation and Program Planning 45, 171-181. https://doi.org/10.1016/j.evalprogplan.2014. 04.003

Driskell, D., 2002, Creating better cities with children and youth: A manual for participation, United Nations Educational, Scientific and Cultural Organization, Paris.

Fanelli, C.W., Musarandega, R. \& Chawanda, L., 2007, 'Child participation in Zimbabwe's national action plan for orphans and other vulnerable children Progress, challenges, and possibilities', Children, Youth and Environments 17(3), Progress,

Freeman, C. \& Tranter, P., 2011, Children and their urban environment: Changing worlds, Earthscan, London.

Freeman, M. \& Mathison, S., 2009, Researching children's experiences, The Guilford Press, New York, NY.

Gordon, L.N., 2015, 'Child participation in Jamaica: Cultural reality versus Idealism', Social and Economic Studies 64(1), 49-74.
Greene, J.C., 1987, 'Stakeholder participation in evaluation design: Is it worth the effort?', Evaluation and Program Planning 10(4), 379-394. https://doi. org/10.1016/0149-7189(87)90010-3

Gregory, A., 2000, 'Problematizing participation: A critical review of approaches to participation in evaluation theory', Evaluation 6(2), 179-199. https://doi.org/ $10.1177 / 13563890022209208$

Guijt, I., 2014, 'Participatory approaches', in Methodological briefs: Impact evaluation 5, UNICEF Office of Research, viewed 22 November 2019, from https://www. unicef-irc.org/publications/750-participatory-approaches-methodological-briefsimpact-evaluation-no-5.html.

Hart, R., 1992, 'Children's participation: From tokenism to citizenship', in Innocent essays, United Nations Children's Fund, viewed 22 November 2019, from http:// www.unicef-irc.org/publications/pdf/childrens_participation.pdf.

Hart, R.A., 1997, Children's participation: The theory and practice of involving young citizens in community development and environmental care, United Nations Children's Fund, London.

Healy, K., 1998, 'Participation and child protection: The importance of context', The British Journal of Social Work 28(6), 897-914. https://doi.org/10.1093/oxford journals.bjsw.a011407

Hickey, S. \& Mohan, G., 2004, Participation from Tyranny to trans-formation?: Exploring new approaches to participation in development, Zed Books, New York, NY.

Hörschelmann, K. \& Van Blerk, L., 2011, Children, youth and the city, Routledge, New York, NY.

James, A., Jenks, C. \& Prout, A., 1998, Theorizing childhood, Teachers College Press, New York, NY.

Kirby, P., Lanyon, C., Cronin, K. \& Sinclair, R., 2003, Building a culture of participation: Involving children and young people in policy, service planning, delivery and evaluation, Department of Education and Skills, London.

Lansdown, G., 2005, Can you hear me? The right of young children to participate in decisions affecting them, Working Paper 36, Bernard van Leer Foundation, The Hague.

Lansdown, G., 2014, A toolkit for monitoring and evaluating children's participation, Save the Children, London.

Lansdown, G., 2019, 'The future of childhood', United Nations Children's Fund, viewed 22 November 2019, https://unicef.libsyn.com/gerison-lansdown-rights-experton-politics-and-the-crc

Liebel, M., 2012, Children's rights from below: Cross-cultural perspectives, Palgrave Macmillan, New York, NY.

Loveridge, J., 2010, Involving children and young people in research in educational settings, University of Wellington, Jessie Hetherington Centre for Educational Research, Victoria.

Lundy, L., 2007, "Voice" is not enough: Conceptualising Article 12 of the United Nations Convention on the Rights of the Child', British Educational Research Journal 33(6), 927-942. https://doi.org/10.1080/01411920701657033

Mikkelsen, B., 2005, Methods for development work and research: A new guide for practitioners, Sage, New Delhi.

Plan International, 2018, Child-friendly feedback mechanisms: Guide and toolkit, Plan International, Surrey.

Powell, M.A., Fitzgerald, R., Taylor, N.J. \& Graham, A., 2012, International literature review: Ethical issues in undertaking research with children and young people, Southern Cross University, Lismore.

Pradhan, U., 2007, 'The child-to-child approach to community and health development in South Asia', Children, Youth and Environments 17(1), 257-268.

Republic of South Africa, 1996, Constitution of the Republic of South Africa.

Republic of South Africa, 2005, Children's Act 38 of 2005, viewed 02 December 2018, from https:// www.justice.gov.za/legislation/acts/2005-038\%20childrensact.pdf.

Samaranayake, M. \& Zaveri, S., 2014, 'Week 17: A Q\&A on working with children in evaluation', Better evaluation, viewed 22 November 2019, from https://www. betterevaluation.org/en/blog/Q\%26A_children_evaluation.

Save the Children South Africa 2019, 'National child participation framework: Childfriendly version', Save the Children South Africa, viewed 30 March 2020, from https://resourcecentre.savethechildren.net/library/national-child-participationframework-child-friendly-version.

Save the Children/Republic of South Africa National Department of Socia Development (SCSA/DSD), 2018, National Child Participation Framework, viewed 02 December 2018, from https://resourcecentre.savethechildren.net/publishers/ republic-south-africa-national-department-social-development.

Skivenes, M. \& Strandbu, A., 2006, A child perspective and children's participation. Children, youth and environments, 16(2), 10-27.

United Nations, 1990, United Nations Convention on the Rights of the child, United Nations Commission on Human Rights, Geneva.

United Nations Children's Fund, 2018, Briefing notes on SDG global indicators related to children, viewed 16 November 2018, from https://data.unicef.org/resources/ sdg-global-indicators-related-to-children/.

Wilkinson, J., 2000, 'Children and participation: Research, monitoring and evaluation with children and young people', Child Rights International Network, viewed 22 November 2019, from https://bettercarenetwork.org/library/social-welfaresystems/data-and-monitoring-tools/children-and-participation-researchmonitoring-and-evaluation-with-children-and-young-people. 